rainfall and of the catchment characteristics, including the limits of retention capacity as influenced by land use and misuse. The hydrological estimate of 'maximum possible floods' or 'probable maximum floods' starts, however, with studies of storm maxima, either by transposing the worst recorded storm for the region on to the catchment in question, or by building up from other meteorological data.

Since the Reservoir (Safety Provisions) Act, 1930, has laid the responsibility for checking the safety of dams upon a panel of engineers, the technique advocated in the Institution of Civil Engineers' Interim Report, 1933, is to plot the peak discharges for all the recorded rivers in Britain in cusecs per thousand acres of catchment for the actual catchment area; the curve thus produced has been of the greatest value as a guide in experienced hands. A revision of this report is now in preparation and will include flood data collected between 1933 and 1957 , and this will be a further step in helping the designers of dams and also those wrestling with flood forecasting.

Local authorities are continually trying to attract new industry to their area, but in many cases do not know what their water resource amounts to. Demands of 5 million gallons a day, or even 20 million, are now met with ; but the number of sites which can cater for such demands is limited, and when the few still to be exploited in England are used up, there will remain only the Scottish Highlands. Unfortunately, we do not know the potential of many Scottish rivers and it is imperative that more data and more reliable data should be collected. Guesses are not good enough; an industrialist will site his factory where he knows there is enough water, and not on another more desirable site where there might be enough.

In the past it has not been the duty of a local authority to measure river flows. It is a highly specialized job and an expensive one if carried out according to the high standards of the Land Drainage Division of the Department of Agriculture for Scotland. The programme of the Division is being greatly extended, but even so, only a fraction of Scottish rivers is now being measured. Under the river purification boards now appointed for eight lowland rivers in Scotland, minimum or nadir flows are being measured, as this is the crucial figure needed to determine permissible pollution. Other county officers, including planners, road engineers and police, want data for safety precautions and flood warning systems, and are adopting various types of gauging less expensive than the Land Drainage Division's specification.

The Royal Scottish Geographical Society has recently established a standing committee for river flow studies and is defraying the expenses of meetings; the group includes the four university geography departments, civil engineers, land drainage and water use specialists, meteorologists and land use planners. The main tasks are to collate flood records, review any research work and encourage fresh efforts in research and survey of river behaviour, and ensure publication of suitable material; to advise local authorities when called upon; and where warranted, to agitate for action on flood control ; to arrange the formation of 'flying squads' for immediate recon. naissance of floods as they occur ; and to encourage longer-term studies bearing upon evapo-transpiration and the ultimate demands on existing water supplies. So far, the committee's main function has been to provide a platform for discussion; the organization is a very long way behind its Danish counterpart, the Hydrology Section of the Danish Heath Society at Slagelse. Hitherto, efforts to get funds have failed and the programme is crippled because of this.

The measurement of the flow of water, starting with surface run-off and finishing in the sea, can properly be considered the sphere of geographers skilled in hydrometry; the basic knowledge must needs include the ecology and geology of the catch. ment as well as the engineering of a gauging site, the best equipment for the given conditions, and the drill for using the instruments properly. Too much of current press writings about floods and water resources shows a superficial approach. It is hoped that this may be counteracted to some extent by getting an increasing number of geographers using a scientific approach and in close collaboration with the engineers to undertake hydrometric work as well as climatological stations, and so build up a fuller knowledge of the nation's water resource.

R. Maclagan Gorrie

\title{
NUCLEAR POWER STATIONS
}

\section{WORLD PLANS AND EXPERIENCE}

\begin{abstract}
$\mathrm{A}$ $\mathrm{T}$ the first Geneva Conference on the Peaceful Uses of Atomic Energy in 1955 only the U.S.S.R. could claim to have a nuclear power station in operation, and that on little more than an experimental scale. Producing 6,000 kW., it was generally considered, from the description provided, to be no more than a demonstration of feasibility. The building of Calder Hall was well advanced, but it was not in operation and its economy and reliability were still to be demonstrated. The United States, with ample and cheap supplies of fossil fuels, felt less urgency for the development of nuclear power stations and greater difficulty in achieving economic parity with conventional stations at home.

The three years between the first and second Conferences at Geneva have seen very great advances
\end{abstract}

in this field in many countries. The feasibility of nuclear power stations is no longer in question and discussion now centres on the type of reactor to be used, the date by which it will provide electricity as cheaply as conventional stations, in particular national economies, and the rate at which nucleas: power stations can be built. In 1955, only the United Kingdom had a national nuclear power programme, and it is significant of the rate of advancement in this period that within two years this programme had been substantially increased, based on the development potential revealed by the design of the first stations. At the second Conference recently concluded, a number of countries presented papers setting out their plans for the construction of nuclear power stations, not as vague and distant hopes, but 
covering generally the next decade and based on careful assessments of demands for electricity, supplies and costs of fossil fuel, the economics of reactor systems and the availability of finance and technological man-power.

Between those countries where fossil fuel or hydro reserves are at present adequate, such as the United States and Sweden, and those which urgently require a new source of energy, such as Japan and Italy, there are a number of differences which have led to two main approaches. The former group tend to have wide ranging programmes of prototype demonstration reactors, whereas the latter concentrate on systems already developed in other countries. Western Europe, through the agency of Euratom, may be in a special position, combining concentration by individual countries with diversity over the whole Euratom area.

Running through most of the papers presenting national programmes is the determination to achieve ultimate independence, at least in the design and construction of the stations, although several countries will clearly have to rely on imports of uranium and thorium for fuel. At the same time, there is recognition of the heavy demands on scientific and technological man-power, as well as on industrial capacity, which the development of a reactor system to a commercial scale makes, and the realization that in the early stages there must be some degree of dependence on other countries.

For those countries which have accepted the need to import their first nuclear power stations, the choice virtually rests between two systems: the graphitemoderated, gas-cooled reactor developed from Calder Hall, and the water-cooled and moderated systems, in the form of the pressurized water reactor at Shippingport and the boiling-water reactor nearing completion at Dresden in the United States.

No very clear picture as to the relative merits of cost of power in these two types of station emerged. The gas-cooled reactor has high capital cost, which may be reduced if it is built for the large outputs of which it is capable, and low fuel costs. The boilingwater reactor, particularly, appears to have low capital costs but these are associated with higher fucl charges. Thus, an economic comparison is very dependent upon the size of station to be built and the rate of interest chargeable to the capital investment. The fact that the former uses natural uranium, thereby eliminating the need for a diffusion plant or the importation of enriched fuel, offers the prospect of earlier national independence.

Although the number of power reactor systems already built and operating is limited, the range will clearly be extended in the near future, with the United States and the U.S.S.R. leading the way in diversity. The United States, having adequate conventional fuel resources, has been concerned chiefly with the development of reactors for submarine propulsion, and in the field of electricity generation has encouraged the construction of power demonstration reactors, of relatively small output, primarily with a view to export. The availability of comparatively cheap enriched uranium has been invaluable in permitting the study of small reactors of various types, but it is noteworthy that the U.S. Atomic Energy Commission has also turned its attention recently to the gas-cooled, graphite-moderated system.

The United Kingdom, while pursuing its policy of concentrating its main effort on developments of
Calder Hall to provide large units for the home market and introducing modifications such as ceramic fuel and beryllium cans to permit higher operating temperatures and consequent greater efficiency, is considering alternatives such as the replacement of graphite by heavy water as the moderator. That such alternatives must satisfy the criterion of offering economic advantages over developments of the Calder Hall type is clear from the announcement of the abandonment of work on the sodium-cooled graphitemoderated system, which was adjudged to offer no economic inducement. Both the United Kingdom and the United States are devoting considerable effort to the longer-term project of a fast fission reactor, and the advantage of the positive breeding gain which this system permits has been widely recognized. Thus, the Japanese paper speaks of relying on foreign thermal reactors for the early stages of the programme, while concentrating Japan's own research and development effort on the design of breeder reactors to be available commercially about 1970 .

Reviewing typical national programmes, it is interesting first to compare the countries in which the need for nuclear power is most urgent. The plan to provide 5,000-6,000 MW. of installed capacity in the United Kingdom by 1966 is well known. In Italy, five organizations are each planning to build a station, the combined electrical output being $900 \mathrm{MW}$., but no precise time-scale is set. The Japanese paper gives detailed economic analyses, both of the cost of stations and the relation of expenditure to the estimated national income. Besides setting targets of $600 \mathrm{MW}$. by 1965 and 7,000 MW. by 1975, it forecasts that the proportion of equipment manufactured in Japan would rise from 60 per cent in the period 1962-65 to 93 per cent after 1967. The Netherlands, with a present import of about half its fuel supplies and an increasing demand, proposes to have 3,000 MW. of nuclear power station capacity installed by 1975 , sufficient to supply 50 per cent of the electrical output. The first step towards this aim is a $100-\mathrm{MW}$. station in operation by 1962 .

France normally imports about 40 per cent of the energy it consumes, the security of which must be dependent on adequate trade balances and also on satisfactory political conditions. The discovery of uranium ores in metropolitan France led to a power programme similar to, but smaller than, the British, in which the most economic system was sought. The early stations, which employ natural uranium and are moderated by graphite and cooled by carbon dioxide, have been designed as prototypes, each differing somewhat from the next (both horizontal and vertical fuel channels have been tried and pressure vessels have been constructed both of prestressed concrete and of steel). The present programme is for two civil power stations to be completed by the middle of 1961 totalling $233 \mathrm{MW}$. This series of reactors is then to be continued by putting into operation every eighteen months an additional plant, more powerful and more efficient than the preceding one.

Western Germany, with no urgent need to supplement conventional sources of power and a tradition of scientific and industrial ability, plans to investigate a range of reactor systems, including some of its own design, and expects by 1965 to have in operation four or five 'demonstration' stations each producing about $100 \mathrm{MW}$. of electricity. These stations will be 
built for utility companies and not for the Government, though it is proposed that one-third of the capital shall come from public funds. With several research reactors from the United. States and the United Kingdom, and bilateral agreements with Canada and the United States for the supply of uranium concentrates and enriched uranium respectively, Western Germany is making great efforts to overcome the handicap of a late start in the field of atomic energy.

At the other end of the scale, both the U.S.S.R. and Poland state that their fossil fuel deposits are adequate and they have no present need for nuclear power, though the Soviet Union makes the exception that it would be useful in certain remote areas. Although they had not reported any new stations since the one they described in 1955, the Russians announced during the Conference the construction of a station in Siberia with an ultimate output of 600 MW.(e). The information given suggests that it is a dual-purpose station with electricity as a by-product. They also showed in the scientific exhibition at the Conference a design for a 150-MW. station using gas-cooled, heavy water-moderated reactors. The Polish programme is based on the conclusion that nuclear stations will be more economic than conventional stations within twenty years, and it is therefore planned to install 800 MW. capacity between 1965 and 1970, with a further $1,000 \mathrm{MW}$. capacity added in the following five years. It is hoped that the reactors in these later stations may be of the fast breeder type.

An interesting variation is provided by Sweden, where the hydro-electric capacity is adequate to meet demands for the next fifteen years, but where there is virtually no domestic conventional fuel. This lack of coal and oil, combined with the long winter, has caused the Swedish programme to be directed towards the use of nuclear energy for district heating, with the production of electricity by backpressure turbines as a by-product. By 1965 it is intended to build six reactors to supply heat and only one 100-MW. electrical power station. As the available hydro resources are fully utilized, an expansion in the nuclear power station programme is envisaged, providing a total installed capacity of about 2,000 MW. by 1975 .

Other countries, including India, Spain and Roumania, presented papers forecasting the construction of nuclear power stations within the next few years.

The range of experience in operating power-produc. ing reactors is at present both limited and unrepresentative, being based largely on units planned primarily for military purposes or on small-scale demonstration reactors. The 80 per cent availability reported for the Calder Hall reactors is gratifying proof of reliability, but the extremely low incidence of defective fuel elements achieved is not conclusive evidence of performance of the power station because of the relatively low level of irradiation imposed by the military requirements. In the same way, the remarkable performance of the submarine reactors cannot be taken as a reliable guide to the behaviour of a similar type of reactor designed to standards which permit the economic generation of electricity. Thus, both the running costs of the present type of power reactors and their span of useful life, which have an important bearing on the assessment of their economics, can only be finally established when a significant proportion of their estimated life of fifteen or twenty years has been achieved.

Nevertheless, there was at the Conference a high degree of confidence in all the countries concerned that these factors would prove to be favourable to the economic generation of power.

\section{UTILIZATION OF INORGANIC NITROGEN SOURCES BY PLANTS}

$\mathrm{O}^{\mathrm{N}}$ NE session of Section K (Botany) of the British Association meeting at Glasgow, held on August 29, was devoted to a consideration of the problems involved in the utilization of inorganic nitrogen sources for amino-acid and protein synthesis by plants. Emphasis was primarily upon the nitrogen fixation process, although recent progress in the use of combined inorganic nitrogen sources was also reviewed.

Dr. G. Bond (Glasgow) stressed that nitrogen fixation constitutes one of the few fundamental processes of the living world and serves to maintain the supply of combined nitrogen in soils and oceans. Without fixation the opposing actions of the denitrifying bacteria would probably reduce the nitrogen status of natural soils to levels incapable of supporting most forms of plant life.

What, then, are the organisms capable of effecting nitrogen fixation? During a critical review of recent evidence gained largely by the use of the heavy isotope of nitrogen (nitrogen-15), Dr. Bond concluded that no faculty for fixation resides in members of the Angiosperms, Gymnosperms, Pteridophytes or Bryophytes except where there is symbiosis with certain lower organisms. Some blue-green algae (Nostoc, Anabaena and Cylindrospermum) have long been recognized as efficient nitrogen fixers. Certain other members of the Cyanophyceae are incapable of fixing nitrogen, as are all green algae so far tested. The position of the fungi is less certain, and much confirmatory work would seem desirable. While the nitrogen nutrition of most fungi would undoubtedly seem to be based on combined nitrogen, there is preliminary evidence that certain fungi (soil yeasts assigned to the genera Saccharomyces and Rhodotorula) have some capacity for fixing nitrogen.

The main free-living nitrogen-fixing organisms are without doubt to be found among the bacteria. 'The genera Azotobacter and Clostridium include species with an almost world-wide distribution that can effect nitrogen fixation. However, it remains uncertain whether they are sufficiently abundant in soils to permit of extensive nitrogen fixation. Other: species for which there is evidence of ability to fix nitrogen include Azotomonas, Aerobacter, Desulphovibrio, Methanobacterium and Pseudomonas ; positive results have also been obtained for photosynthetic bacteria, including Rhodospirillum, Chromatium and Chlorobium, and so these species match the Cyanophyceae in metabolic powers.

In many plant habitats symbiotic nitrogen fixation is probably much more important than any of the 